\title{
PERFIL EPIDEMIOLÓGICO DOS CASOS DE SÍFILIS EM GESTANTES NO MUNICÍPIO DE SALVADOR, BAHIA, DE 2015 A 2019
}

\author{
EPIDEMIOLOGICAL PROFILE OF SYPHILIS CASES IN PREGNANT WOMEN \\ IN THE CITY OF SALVADOR, BAHIA, FROM 2015 TO 2019
}

Tatiana Cibelle de Souza Silva*, Gabriel Gonçalves Batista dos Reis, Alexandre Magno Teixeira de Medeiros.

Centro Universitário Faculdade de Tecnologia e Ciências, Salvador, BA, Brasil. *tatianacibelle@gmail.com

\section{RESUMO}

A sífilis é uma doença infectocontagiosa e sexualmente transmissível que quando ocorre no período gestacional, pode causar sérios riscos à saúde materno-fetal. Nesse contexto, traçar o perfil epidemiológico dos casos notificados de sífilis na gestação é importante para que políticas e ações públicas em saúde possam ser aprimoradas visando prevenir complicações, como a sífilis congênita. Este estudo teve como objetivo analisar o perfil epidemiológico dos casos notificados de sífilis em gestantes no município de Salvador-BA entre janeiro de 2015 e dezembro de 2019. Trata-se de um estudo epidemiológico, observacional, transversal e retrospectivo de caráter descritivo realizado através da coleta dos dados secundários disponibilizados pela Superintendência de Vigilância e Proteção da Saúde. São informações de domínio público, sem possibilidade de identificação, estando isento da necessidade de registro e avaliação pelo sistema CEP/CONEP e de termo de consentimento livre e esclarecido. Através da análise dos dados coletados, verificou-se a ocorrência de 625 casos em 2015, 954 em 2016, 892 em 2017, 1371 em 2018 e 1303 em 2019. No total, foram notificados 5.145 casos de sífilis gestacional em Salvador no período estudado, sendo que 4.845 correspondiam a gestantes residentes no município e $32,9 \%$ dos registros ocorreram fora da assistência pré-natal. A análise mostra que $51,7 \%$ das gestantes possuem pele parda e que $51.5 \%$ foram diagnosticadas na faixa etária de 20-29 anos. Verifica-se que das 3018 que relataram algum grau de escolaridade, $41,3 \%$ não haviam concluído o ensino fundamental e $37,7 \%$ tiveram esse dado ignorado. $O$ tratamento do parceiro foi realizado em 45,49\% das vezes e não houve registro dessa informação em 1566 casos. Das gestantes com sífilis, 1402 foram diagnosticadas no estágio de sífilis latente. Analisando os dados, pode-se inferir que houve um aumento crescente de casos notificados, mostrando a importância dessa patologia como um problema de saúde pública. Estes resultados mostram a importância do desenvolvimento de ações voltadas para prevenção de infecções sexualmente transmissíveis e planejamento familiar. O elevado número de casos diagnosticados fora da assistência pré-natal reforça a necessidade de melhorias na captação e acompanhamento das gestantes pela atenção primária em saúde, para garantir a saúde materno-fetal através da realização de um pré-natal adequado. A importância do diagnóstico laboratorial é notada devido à prevalência de sífilis latente, a qual é assintomática, não sendo possível o 
diagnóstico clínico. Além disso, o pequeno número de parceiros tratados pode ser resultado da falta de planejamento familiar ou abandono da mulher grávida, além da baixa adesão masculina aos sistemas de saúde, gerando riscos sociais como reinfecção e aumento no número de casos de sífilis congênita.

Palavras-chave: Cuidado pré-natal. Estudos transversais. Gestantes. Saúde materna. Sífilis. 